\title{
Effect of phosphoric acid and perchloric acid on Electropolishing of additive manufactured 17-4 PH stainless steel and its characterization
}

\author{
Chia-Yu Lee ${ }^{1}$, Ming-Der Ger ${ }^{2,5}$, Jung-Chou Hung ${ }^{3}$, Po-Jen Yang ${ }^{3}$, Yi-Cherng Ferng ${ }^{4}$, \\ Kuo-Kuang Jen ${ }^{4}$, Shun-Yi Jian ${ }^{2,5, *}$ \\ ${ }^{1}$ Graduate School of Defense Science, Chung Cheng Institute of Technology, National Defense \\ University, Taoyuan, Taiwan \\ ${ }^{2}$ Department of Chemical \& Materials Engineering, Chung Cheng Institute of Technology, National \\ Defense University, Dasi district, Taoyuan City 335, Taiwan \\ ${ }^{3}$ Department of Mechanical Engineering, National Central University, Chung-Li 320, Taiwan \\ ${ }^{4}$ Missile and rocket systems research division, National Chung-Shan Institute of Science and \\ Technology, Taoyuan City 32546, Taiwan \\ ${ }^{5}$ System Engineering and Technology Program, National Chiao Tung University, Hsinchu City 300, \\ Taiwan \\ *E-mail: ftvko@yahoo.com.tw
}

Received: 29 November 2021 / Accepted: 9 January 2022 / Published: 2 February 2022

Additive manufactured 17-4 PH stainless steel is widely used and is the material for this study. The processing of the work piece for additive manufacturing is difficult and the surface is very rough. The surface roughness is reduced by electropolishing using phosphoric acid and perchloric acid solutions, in order to compare their efficiency. Surface morphology is determined using SEM. A 3D white light interferometer measures the surface roughness and electrochemical testing is used to determine corrosion resistance after electropolishing.

Keywords: Electropolishing; Additive Manufacturing; 17-4 PH stainless steel; Surface roughness

\section{$\underline{\text { FULL TEXT }}$}

(C) 2022 The Authors. Published by ESG (www.electrochemsci.org). This article is an open access article distributed under the terms and conditions of the Creative Commons Attribution license (http://creativecommons.org/licenses/by/4.0/). 